\title{
Therapeutic Efficacy
}

National Cancer Institute

\section{Source}

National Cancer Institute. Therapeutic Efficacy. NCI Thesaurus. Code C70924.

The ability of a chemical agent or a device to treat a disease. 